\title{
Device or Fragments Remain in Patient
}

National Cancer Institute

\section{Source}

National Cancer Institute. Device or Fragments Remain in Patient. NCI Thesaurus. Code C118640.

A device or pieces of the device remain in a patient. 